I wish to thank Mr. A. H. Thomson, the Consultant General Surgeon, General Hospital, Burnley, Lancashire, under whose care this case was admitted and whose constant encouragement and help made this report possible. I would also like to thank Miss Wardle, the Librarian at the Royal College of Surgeons of Edinburgh, for her help in arranging the bibliography.

\section{REFERENCES}

Douglas, D. M. (1942): Strangulated Hernia - a Consideration of Some Factors Affecting the Mortality, Brit. Med. J., i, 354.
Frankau, Claude, (1931): Strangulated Hernia. A Review of 1487 Cases, Brit. J. Surg., 19, 176.

MaIngot, Rodney (1955): Abdominal Operations, 3rd Edition, 1053 London: H. K. Lewis.

McEvedy, P. G. (1950): Femoral Hernia, Ann. Roy. Coll. Surg. Engl., 7, 484

OGILVIE, H. (1959): Hernia, 98, London: Edward Arnold.

ShePHERD, J. A. (1960): Surgery of the Acute Abdomen, p. 1040, Edinburgh \& London: E. \& S. Livingstone.

WAKeley, C. P. G. (1938): Hernia of the Vermiform Appendix, A Record of 16 Personal Cases, Lancet ii, 1282.

\title{
HEREDITARY HAEMORRHAGIC TELANGIECTASIA WITH PULMONARY ARTERIO-VENOUS FISTULAE
}

\author{
VAlentine U. Dewar \\ Medical Student, \\ University of St. Andrews
}

\author{
Malcolm Schonell, M.B., B.S., M.R.C.P.E. \\ Lecturer, Department of Respiratory Diseases, \\ University of Edinburgh
}

Hereditary haemorrhagic telangiectasia was described by Rendu (1896), Osler (1901) and Weber (1907). Whitaker (1947) reported two patients with hereditary haemorrhagic telangiectasia and cavernous haemangioma (arterio-venous fistula) of the lung. He suggested that the lung lesion was a manifestation of hereditary telangiectasia. This association is relatively uncommon.

\section{Case Report}

A European married woman aged 35 years was admitted to hospital in November 1965 for treatment of a rectal neoplasm. On 4th November, 1965 abdominoperineal resection was carried out and histological examination of the operative specimen was reported as showing malignant change in an adenopapilloma. Eight hours post-operatively the patient developed a right hemiparesis which gradually resolved during the following week. On the 20th December 1965 she suddenly developed left pleuritic chest pain accompanied by sweating, tiredness and transient weakness and paraesthesiae of the left hand. One week later she experienced right pleuritic pain and was referred to this unit for assessment of her chest symptoms.

The patient had had pertussis at the age of 10 years and following left pleurisy at the age of 20 she had suffered from an unproductive cough and exertional breathlessness. In 1957 appendicectomy was performed. A fibroadenoma was removed from the right breast in 1962 and she was first noticed to have gross clubbing of the fingers at this time. She gave a history of frequent nose bleeds since childhood, the epistaxis usually occurring spontaneously and being more copious during menstruation. The patient's son and two nieces also suffer from recurrent epistaxis.

On admission the patient was noted to have marked clubbing of the fingers and slight central cyanosis. No abnormalities were detected on palpation or auscultation of the precordium. A loud systolic murmur was audible over the right lower lobe, maximal in intensity in the mid-axillary line. The intensity of the murmur was increased by deep inspiration and diminished by the Valsalva manoeuvre. There were telangiectases on the mucosal aspects of the upper and lower lips, tongue, palate and nasal mucosa and one telangiectasis on the conjunctiva of the right upper eyelid. The optic fundi were normal and liver and spleen were not palpable.

Chest X-ray showed a rounded opacity $2 \mathrm{~cm}$. in diameter in the periphery of the right lower zone and four small opacities approximately $0.5 \mathrm{~cm}$. in diameter inferior to the large opacity. Tomograms of the right lower zone showed that the large opacity had a comma-like configuration with two large vessels communicating with it (Fig. 1). The presence of these vascular communications was confirmed on screening of the chest although the Valsalva manoeuvre did not produce any noticeable change in the size of the opacity. It was decided that this radiological abnormality was due to pulmonary arterio-venous fistulae. Bronchography showed minimal bronchiectasis of the left lower lobe.

Investigations: Hb. $84 \%$ (12.3 g./100 ml.; PCV 42\%; MCHC $29.5 \%$; WBC 6,500/cu. mm., normal differential; platelets 255,000/cu. mm.; ESR $11 \mathrm{~mm}$./hr. Arterial blood gas analysis at rest gave the following results: oxygen saturation $84 \%$; carbon dioxide content 40.4 ml./100 ml.; pH 7.46; carbon dioxide tension $30 \mathrm{~mm}$. Hg. Ventilation tests showed a forced vital capacity of $3100 \mathrm{ml}$.; FEV $1,1900 \mathrm{ml}$. ECG, left axis deviation; flat $\mathrm{T}$ waves in leads II, III and aVF.

A diagnosis of hereditary haemorrhagic telangiectasia with pulmonary arterio-venous fistulae was made. Histological review of the rectal tumour and of the breast fibroadenoma did not show any abnormal vascular components. These lesions were presumably unrelated to the hamartomatous syndrome. Measurement of lung volumes, exercise studies and pulmonary angiography were not undertaken since it was considered unjustifiable to subject this unfortunate patient to further anxiety and discomfort. At present it is proposed to observe her at regular intervals.

The patient's son, aged 12 years, and two nieces, aged 16 and 11 years, have been examined because of their history of epistaxis. The two nieces did not show evidence of telangiectasia but the patient's son has a number of telangiectases on his face and lips. It seems likely that he has hereditary haemorrhagic telengiectasia. 


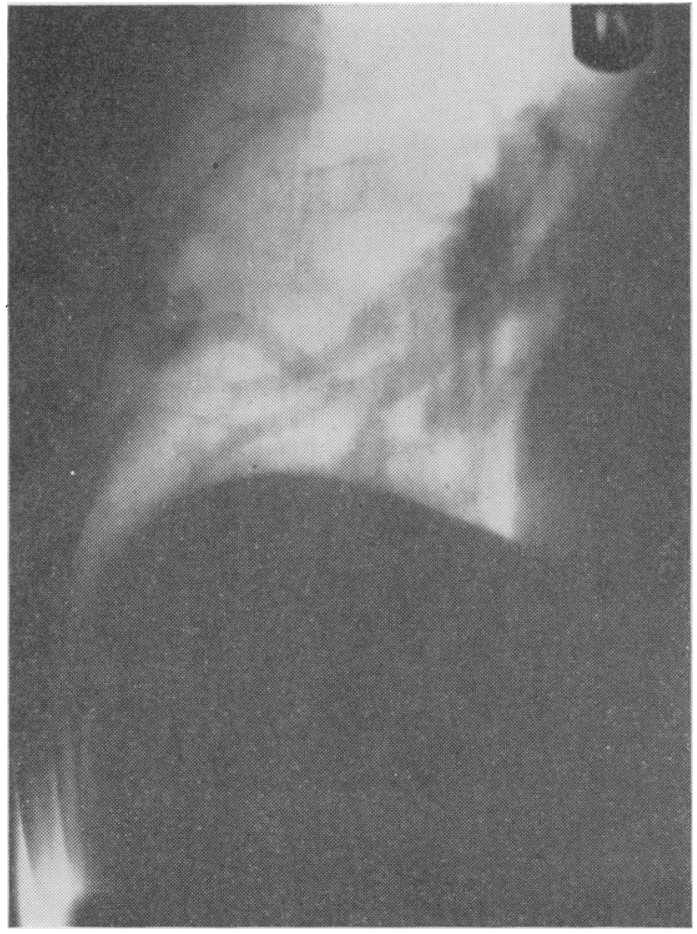

FIG. 1.- Tomogram of right lower zone showing pulmonary arterio-venous fistulae.

\section{Discussion}

Hereditary haemorrhagic telangiectasia is a congenital vascular abnormality which is transmitted as a simple Mendelian dominant affecting both sexes equally. This developmental vascular malformation may be classified as a hamartoma (Willis, 1962). The telangiectases involve skin and mucus membranes and are seen most commonly on the face, hands and feet, occurring with increasing frequency after puberty. It is possible that this patient's son may develop more telangiectases later. The commonest symptom is epistaxis and in women this may be related to periods of low oestrogen secretion and high urinary gonadotrophin excretion (Koch, Escher and Lewis, 1952). This does not explain why the patient had noticed that her nose bleeds more profusely when she is menstruating. Telangiectases also occur in the gastro-intestinal tract, genito-urinary tract, liver and spleen, brain and lung, and recurrent bleeding from these lesions may cause iron-deficiency anaemia. The platelet count, clotting time and other tests of coagulation are normal and bleeding occurs readily because the telangiectases are lined by only a thin layer of endothelial cells (de Gruchy, 1960).

The incidence of pulmonary arterio-venous fistulae in patients with hereditary haemorrhagic telangiectasia has been studied by Hodgson, Burchell, Good and Clagett (1959) and Hodgson and Kaye (1963). In a review of a large family, 91 members were found to have telangiectases and of these, 16 (17.6 per cent) had pulmonary arterio-venous fistulae. Moyer, Glantz and Brest (1962) in a review of the world literature state that out of a total of 220 patients with pulmonary arterio-venous fistulae, 78 patients ( 35 per cent) had telangiectasia.

Pulmonary arterio-venous fistulae occur most commonly in the right lower lobe and are not infrequently multiple and bilateral. The clinical features are cyanosis, breathlessness, clubbing of the fingers and an extra-cardiac murmur. Cyanosis results from shunting of unoxygenated blood. It is stated that at least 25 per cent of the blood must be shunted past the pulmonary capillary bed before cyanosis is clinically detectable (Alexander and Harrington, 1955). The cardiac output is usually normal in such patients. The murmur is due to flow of blood through the fistulae and is usually systolic but may be continuous with systolic accentuation. The Valsalva manoeuvre, which causes increased intrathoracic pressure and diminished blood flow through the lungs, may cause the murmur to disappear. Polycythaemia is usually present in patients with pulmonary arterio-venous fistulae and is due to the associated anoxia. In this patient the absence of polycythaemia may have been the result of recurrent epistaxis and blood loss at her recent operation. Alexander and Harrington (1955) reported cerebral symptoms such as syncope, convulsions transient paresis, paraesthesiae, visual and auditoryo disturbances and speech defects in 27 per cent of patients with pulmonary arterio-venous fistulae. These manicō festations have been attributed to polycythaemia, cerebral anoxia, cerebral embolism or cerebral telangiectasia. It is difficult to be sure of the exact cause of this patient's post-operative cerebral symptoms but it would seem that they developed against a background of cerebral anoxia. The patient's pleuritic pain was possibly due to pulmonary infarction or infection. A radiographic pulmonary opacity is usually present in patients with pulmonary arterio-venous fistulae although there have been reports of patients in whom the chest X-ray was normal (Cooley and McNamara, 1954; Apthorp and Bates, 1957). The typical radiographic appearance is similar to that described in this patient, Frequently surgical resection is recommended because of the risks of haemorrhage, infection and neurological complications. Prior to operation pulmonary angiography should be carried out to exclude multiple fistulae (Le Roux, 1959). When resection is not performed the patient should have an annual chest X-ray to detect any increase in size of the fistula.

\section{Summary}

A case of hereditary haemorrhagic telangiectasia with pulmonary arterio-venous fistulae is described.

We would like to thank Professor John Crofton for allowing us to report this case and are grateful for his advice. It is a pleasure to acknowledge the secretarial assistance of Miss Joyce Holywell. 


\section{REFERENCES}

Alexander, L. L. and Harrington, L. A. (1955): Multiple Arteriovenous Fistulas of Lung, N.Y. St. J. Med., 55, 2807.

APthorp, G. H. and BATES, D. V. (1957): Report of a Case of Pulmonary Telangiectasia, Thorax, 12, 65 .

Cooley, D. A. and McNamara, D. G. (1954): Pulmonary Telangiectasia: Report of a Case Proved by Pulmonary Biopsy, J. thorac. Surg., 27, 614.

DE GRUCHY, G. C. (1960): "Clinical Haematology in Medical Practice," Oxford: Blackwell Scientific Publications.

Hodgson, C. H., Burchell, H. B., Good, C. A. and ClageTt, O. T. (1959): Hereditary Haemorrhagic Telangiectasia and Pulmonary Arteriovenous Fistula: Survey of a Large Family, New Engl. J. Med., 261, 625.

Hodgson, C. H. and KAYE, R. L. (1963): Pulmonary Arteriovenous Fistula and Hereditary Haemorrhagic Telangiectasia: A Review and Report of 35 Cases of Fistula, Dis. Chest, 43, 449.

Koch, H. J. JR., Escher, G. C. and Lewis, J. S. (1952):
Hormonal Management of Hereditary Haemorrhagic Telangiectasia, J. Amer. med. Ass., 149, 1376.

LE Roux, B. T. (1959): Pulmonary Arteriovenous Fistulae, Quart. J. med., 28, 1.

MoYeR, J. H., Glantz, G. and BREST, A. N. (1962): Pulmonary Arteriovenous Fistulas: Physiologic and Clinical Considerations, Amer. J. Med., 32, 417.

OsLER, W. (1901): Family Form of Recurring Epistaxis, Associated with Multiple Telangiectases of the Skin and Mucous Membranes, Bull. Johns Hopk. Hosp., 12, 333.

Rendu, M. (1896): Epistaxis Répétées Chez un Sujet Porteur de Petits Angiomes Cutanés et Muqueux, Gaz. Hop. (Paris), 1322.

WEBER, F. P. (1907): Multiple Hereditary Developmental Angiomata (Telangiectases) of the Skin and Mucous Membranes Associated with Recurring Haemorrhages, Lancet, ii, 160.

WHITAKER, W. (1947): Cavernous Haemangioma of Lung, Thorax, 2, 58.

WiLLIS, R. A. (1962): "The Borderland of Embryology and Pathology." London: Butterworth.

\title{
THIAZIDE DIABETES
}

\author{
E. L. Harris, M.B., M.R.C.P., M.R.C.P.(Ed.) \\ R. O. F. HaRdwick, M.B., M.R.C.P. \\ Diabetic Clinic, West Kent Hospital, Maidstone.
}

IN 1959 the first reports of impairment of carbohydrate metabolism by benzothiadiazine appeared in the medical press (Wilkins, 1959; Freis, 1959; Finnerty, 1959). Since then there have been further reports of diabetes secondary to these drugs (Suger, 1961; Dollery, Pentecost and Samaan, 1962; and Samaan, Dollery and Fraser, 1963). Shapiro, Benedek and Small (1961) described five cases of "thiazide diabetes" which was characterised by delayed onset in elderly patients, manifested primarily by hyperglycaemia but without acidosis, controlled readily with insulin, and eventually reversible. Goldner, Zarowitz and Aksun (1960) confirmed the reversibility of the condition: although Samaan and others (1963) found a lessening in severity of the diabetic state after discontinuation of therapy, they had not at that time observed a full remission. A fatal case of diabetic coma (Cranston, Juel-Jensen, Semmence, Handfield, Forbes and Mutch, 1963) supported the findings of other workers that ketoacidosis was usually absent in this type of diabetes. However, Sugar (1961) reported the occurrence of diabetic acidosis in two pregnant women after chlorothiazide therapy.

It was initially suggested that thiazide-induced diabetes only occurred in "potential diabetes" or in prediabetic subjects. Potential diabetes is considered as such when subjects have a glucose tolerance curve with peaks at $180 \mathrm{mg} . / 100 \mathrm{ml}$. or above, one hour after a standard glucose load (Shapiro and others, 1961), and pre-diabetes is defined as that in individuals who have a family history of diabetes, fasting glucose levels repeatedly above $100 \mathrm{mg} . / 100 \mathrm{ml}$. and abnormal glucose tolerance tests, the criteria of which require that the blood glucose level was over $160 \mathrm{mg} . / 100 \mathrm{ml}$. in one hour or over $110 \mathrm{mg} . / 100 \mathrm{ml}$. in two hours (Mustala and Toivonen, 1965). Later it became evident that hyperglycaemic effects could be produced in "normal" subjects who fell outside this definition. The absence of ketoacidosis has been an interesting feature in some of the cases especially where high blood glucose levels were found.

We describe the first reported case of diabetes induced by cyclopenthiazide (as Navidrex K) in a "normal" subject who has made a full recovery.

\section{Case Report}

A 57-year-old male school-teacher whose normal weight is $170 \mathrm{lbs}$. was first seen by his general practitioner in December 1964, when he complained of blurring of vision because of difficulty in focusing his eyes.

On examination the important finding was a mild hypertension of $190 / 110 \mathrm{~mm}$. Hg. with Grade 2 retinopathy. His urine was free of albumin and sugar. Treatment was commenced with methyldopa $250 \mathrm{mg}$. b.d. and Navidrex K tabs 1 b.d. By February 1965 his blood pressure had fallen to $170 / 100$ and he felt very much better.

On 21st April he was admitted to hospital with a history of urinary frequency, excessive thirst, progressive weakness and drowsiness for two weeks, and for two days 